\title{
LETTERS
}

\section{Priority reviews: innovation and safety}

In the CMAJ news story about the anticorruption symposium held in Toronto, Dr. Supriya Sharma, chief medical officer at Health Canada, said that the expedited 180-day priority review is justified. Her position was that, even though these drugs have more safety problems once they reach the market, it is an acceptable trade-off because they offer major benefits. ${ }^{1}$ However, that assertion is simply not true for the most part.

First, Health Canada gave a priority review to one-quarter of all the new drugs approved between 1997 and 2012, but fewer than one in six actually offered a major new therapeutic improvement. ${ }^{2}$ Second, Health Canada is not able to predict accurately which drugs should get a priority review. Out of 91 products that got such a review, only 33 were actually major therapeutic innovations. ${ }^{2}$

The bottom line is that faster drug reviews lead to more safety problems ${ }^{3}$ but only occasionally to getting really useful drugs to market more quickly.

\section{Joel Lexchin MD}

Physician, Emergency Department, University Health Network; Professor Emeritus, School of Health Policy and Management, Faculty of Health, York University, Toronto, Ont.

Cite as: CMAJ 2017 July 4;189:E895. doi: 10.1503/cmaj.733103

\section{References}

1. Vogel L. Experts blame feds for pharma corruption. CMAJ 2017;189:E327-8.

2. Lexchin J. Health Canada's use of its priority review process for new drugs: a cohort study [published erratum in BMJ Open 2015;5:e006816corr1]. BMJ Open 2015;5:e006816.

3. Lexchin J. New drugs and safety: What happened to new active substances approved in Canada between 1995 and 2010? Arch Intern Med 2012; 172:1680-1.

Competing interests: Joel Lexchin received consultant fees for projects looking at indication-based prescribing and at which drugs should be distributed free of charge by general practitioners. He received compensation for being on a panel that discussed expanding drug insurance in Canada. He is a member of the Foundation Board of Health Action International. 